\title{
Apuntes
}

\section{Sistemas de ayuda a la navegación}

\author{
Enrique Suárez Pedrique \\ Ingeniero Técnico Naval
}

La navegación marítima es una ciencia cuyo conocimiento permite "andar por el mar" con seguridad, con economía y del modo más práctico. Para ejercer esta ciencia es necesario utilizar y conocer una serie de elementos que ayudan a que las embarcaciones arriben a puerto de forma puntual y segura.

Las ayudas a la navegación quedan definidas como cualquier dispositivo visual, acústico o radioeléctrico destinado a mejorar la seguridad de la navegación y a facilitar sus movimientos, tanto en sus travesias como en los accesos a las instalaciones portuarias. Existen tres tipos de ayudas a la navegación:

> Visuales dotadas o no de luz.

$>$ Acústicas basadas en la emisión de sonidos.

$>$ Radioeléctricas que emplean la emisión o recepción de ondas electromagnéticas.

\section{Ayudas visuales}

Han sido siempre las clásicas ya que se dirigen directamente a los sentidos del navegante y no es necesario llevar a bordo instrumentos especiales para su detección. El mensaje que comunican se identifica con facilidad y es posible determinar la zona en la que nos encontramos consultando en los libros de derroteros o libros de faros y la carta náutica de la zona.

Las ayudas visuales podemos clasificarlas en ciegas y señales luminosas. Las ciegas transmiten su mensaje durante el día, mientras que la luminosa se encarga de transmitir el mismo mensaje durante la noche. Las principales señales visuales, de las cuales hablaremos a continuación, son: faros, balizas, luces de puerto y enfilaciones, entre otras.

\section{Los faros}

Recibe el nombre de faro el conjunto formado por el foco luminoso, la fuente de alimentación, el sistema óptico, el mecanismo de giro y la torre que alberga estos elementos, así como todo aquello que sirve para su funcionamiento. La misión de todos ellos es hacer de guía a los navegantes durante la noche.

A lo largo de las costas, sobre las piedras que velan o los bajos sumergidos, se construyen los faros y la altura dependerá del alcance geográfico que se pretenda conseguir. El alcance luminoso de los faros es mayor de 10 millas náuticas.

Para facilitar el reconocimiento de los faros y de toda señal luminosa en general se producen artificialmente unas alternancias de luz y de oscuridad que se repiten a intervalos iguales de tiempo. Esta alternancia de luz y su color forman una de las caracteristicas de los faros. Así, otra característica importante es el alcance geográfico, que no es otra cosa que la distancia máxima a la que un observador al nivel del mar ve la luz que emite. Los colores universalmente adoptados son el blanco, verde y rojo. De este modo, en condiciones atmosféricas particulares, la luz blanca y a veces también la verde pueden adquirir un tono rosado. En función de las señales luminosas que emiten se clasifican en: faro de luz fija blanca, faro de destellos blancos, faro de luz centelleante, faro de grupos de destellos, faro de grupos de ocultaciones, faro de luz alternativa: roja, blanca y verde.

Desde finales del siglo XVIII, la iluminación de los faros ha ido evolucionando. Así, de la hoguera de leña o carbón se pasó a las mechas introducidas en cebos 0 aceites y a combustibles gaseosos, hasta llegar a los sistemas actuales de lámparas de incandescencia, haz sellado, lámparas halógenas, etc. La fuente de energía más utilizada en la actualidad para su alimentación es la eléctrica, se usan además las energías renovables como la fotovoltaica o la eólica.

\section{Las balizas}

Se denomina asi a cada una de las señales fijas o flotantes con que se indican los bajos, veriles, ejes de ríos y canales, peligros, naufragios y cualquier otros puntos de evidente interés para la seguridad de la navegación. Las balizas mas comúnmente empleadas son las boyas. De este modo, la forma, dimensiones y numeración de las balizas, así como el color, las características de las señales luminosas y marcas de tope que suelen llevar, los fija para cada caso el Reglamento de Balizamiento Marítimo AISM. Habitualmente, las balizas, cuando hay niebla o mal tiempo, son difíciles de localizar, por ello hoy día existen balizas provistas de reflectores de radares. Según el Reglamento las balizas o marcas se clasifican en:

> Marcas laterales: Sirven para indicar los lados de los canales de navegación. En las maniobras de entrada, las de color rojo y luz roja hay que dejarlas por babor y las de color verde y luz verde por estribor.

> Marcas cardinales: Su misión es la de indicar el lado donde hay más seguridad de paso, están pintadas con franjas horizontales de color amarillas y negras. La luz es blanca centelleante.

> Marcas de peligro aislado: Se colocan sobre una zona de peligro de área reducida, alrededor de la cual se puede navegar. Así, la característica más sobresaliente de las marcas de peligro aislado - pintadas en franjas horizontales rojas y negras - es la marca de tope, que consiste en dos esferas negras superpuestas. La luz es blanca de dos destellos.

> Marcas de aguas navegables: Indican los lugares más seguros para navegar, como son los ejes de los canales. Están pintadas de franjas verticales rojas y blancas, y están provistas de luz de isofase o de ocultación. 


\section{Información del PH \\ Sistemas de ayuda a la navegación \\ Enrique Suárez Pedrique}

> Marcas especiales: Para señalizar zonas especiales, son de color amarillo y de forma totalmente distinta a las anteriores. La luz es amarilla.

\section{Las luces de puerto}

Se sitúan en los morros de los espigones de abrigo, en los extremos de los muelles o en los bordes de las zonas dragadas teniendo por misión facilitar la entrada y la salida a los puertos. Entrando, la de estribor es de color verde y la de babor es de color rojo.

\section{Las enfilaciones}

Marcan rutas seguras para llegar a puerto. La enfilación es un caso particular de la demora, pues se da en el preciso instante en el que el buque observa dos puntos bajo un mismo ángulo. Estos puntos vienen perfectamente señalizados en las cartas náuticas.

\section{Ayudas acústicas}

Las ayudas acústicas basadas en la emisión de sonidos no tienen demasiada utilidad, ya que no permiten al navegante fijar la posición con respecto a ellas, aunque su empleo como señal de peligro sigue siendo aconsejable en ciertos entornos y están regidas por el Reglamento Internacional para Prevenir los Abordajes en el Mar. Las más utilizadas en la actualidad son las campanas, gongs y las sirenas de aire comprimido o de vibradores electromagnéticos. Las ayudas acústicas según el Reglamento se clasifican en:

> Señales de maniobra y advertencias.

$>$ Señales acústicas en visibilidad reducida (niebla).

> Señales para llamar la atención.

$>$ Señales de peligro.

Estas señales acústicas se basan en:

> "Pitada corta" o sonido corto, que significa un sonido con una duración de aproximadamente un segundo.

> "Pitada larga" o sonido largo, que significa un sonido de una duración aproximada de cuatro a seis segundos.

De esta manera, la combinación de estos sonidos determinan las distintas señales acústicas relacionadas anteriormente.

\section{Ayudas radioeléctricas}

Estas ayudas nacieron como complemento de las visuales al depender estas últimas de las condiciones atmosféricas del momento. Estas ayudas han evolucionado enormemente y se han convertido en las ayudas del futuro al no depender de las condi- ciones atmosféricas y alcanzar grandes distancias, algunas de ellas incluso de todo el globo terráqueo.

Entre las ayudas radioeléctricas más utilizadas se encuentran los radiofaros -actualmente en desuso en la mayoría de los países-, racones, intensificadores de blancos de radar (RTE), dispositivos de control de tráfico de buques (VTS), sistemas de navegación hiperbólicos (LORAN-C, DECCA) y sistemas de navegación basados en satélites (GPS, DGPS/ EGNOS/ GLONAS, GALILEO).

El dispositivo de gestión de buques VTS (Vessel Traffic Service) es una ayuda a la navegación muy útil en las zonas de gran densidad de tráfico marítimo. Se basa en una red más o menos amplia de radares, junto con una información muy completa de la zona -cartas náuticas electrónicas, datos meteorológico y oceanográfico y condiciones en que se encuentran los buques objetos del seguimiento- y las comunicaciones por voz, normalmente en VHF y GSM. Con estas herramientas es posible estimar las rutas futuras de los diferentes buques y tratar de modificar aquellas que pudieran dar lugar a colisiones o embarrancamientos, haciendo las recomendaciones pertinentes y comprobar la efectividad de las mismas.

Una de las caracteristicas fundamentales de este dispositivo es la posibilidad de ofrecer un servicio de información al navegante, un servicio de asistencia a la navegación y un servicio de ordenación del tráfico.

En relación con el tipo de servicio que ofrece, se distinguen los VTS portuarios, destinados al tráfico que entra y sale de un puerto o instalaciones portuarias y los VTS Costeros, destinados al tráfico que pasa por la zona. Los primeros suelen contar con los tres servicios y los segundos únicamente con el servicio de información.

El Servicio de Información se basa en la radiodifusión de datos a horas determinadas, cuando el VTS lo considere oportuno o a petición de un barco. Garantiza la información necesaria para la toma de decisiones a bordo de los buques, esta información versa sobre:

> Posición, identidad, intenciones y destinos de los barcos en la zona.

> Modificaciones y cambios en la información difundida acerca de la zona, canales o frecuencias de radios que se deben utilizar. > Variables que puedan influir en la navegación tales como: condiciones meteorológicas y oceanográficas, situación de cogestión de tráfico y buques con problemas de navegabilidad, entre otras.

El Servicio de Asistencia a la Navegación presta ayuda a los buques, tanto en las medidas a tomar en un determinado momento, como en el seguimiento de sus efectos. Es especialmente im- 
portante cuando se presentan dificultades para la navegación por motivos meteorológicos, fallos mecánicos, etc. El tipo de información que facilita se refiere a:

$>$ Rutas y velocidad recomendada.

$>$ Posición respecto al eje del canal de entrada o a puntos notables.

$>$ Avisos a barcos determinados.

Este servicio se presta a petición del buque o cuando la VTS lo crea conveniente.

El Servicio de Ordenación de Tráfico tiene por objetivo la gestión del tráfico, facilitando un tráfico seguro y eficiente en la zona servida por el VTS. Este servicio planifica los movimientos de los buques para prevenir que se produzcan congestiones o situaciones de peligro.

Racones es el nombre con el que se designa a una baliza que responde al radar, o sea, una baliza provista de un transmisor que, al recibir los impulsos emitidos por el radar de un buque, entra en funcionamiento y emite unos impulsos que, al ser captado por la antena de abordo, producen una imagen bien visible en la pantalla. Por lo tanto es susceptible de ser empleada para determinar la posición relativa del buque respecto a la baliza.

Los Sistemas de Navegación Hiperbólicos están basados en la obtención del azimut de la estación emisora y la medición del tiempo empleado por la señal de radio para llegar desde el transmisor de tierra hasta el receptor de a bordo. 0 bien, en la medición de la diferencia de tiempo o de fase con que llegan al receptor de a bordo dos señales transmitidas por dos estaciones costeras, en forma más o menos sincronizadas, situadas a cierta distancia entre sí.

Para estos sistemas, además de los sistemas receptores especiales de elevado costo, se necesita que los buques lleven a bordo cartas náuticas especiales.

Sistemas de navegación por satélites basados en la localización del barco en tiempo real mediante la información que van enviando una serie de satélites que orbitan en el espacio. Estas señales de radio determinan la posición del buque en cualquier parte del mundo. Además de la posición, también nos facilita la velocidad real de navegación, el tiempo real de llegada al punto fijado y los desvíos con respecto al rumbo trazado. Con este sistema se pueden trazar rutas, posición de "Hombre el Agua" en caso de caídas accidentales de personas al agua.

Los sistema de navegación por satélites actuales disponen de un plotter o representador gráfico donde, además de visualizar

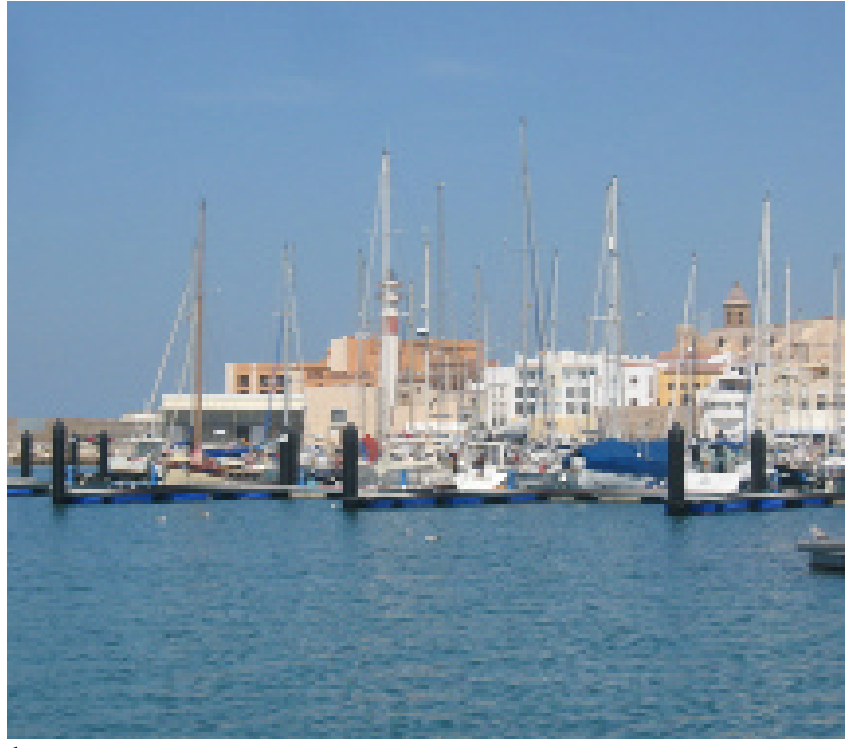

los datos que nos suministran los satélites, podemos introducir cartografía electrónica que nos visualiza la carta náutica de la zona de navegación, así como la posición del buque sobre la misma.

\section{Sistemas de supervisión remota}

Los sistemas de supervisión remota, tengan o no telecontrol, contribuyen a mejorar el servicio prestado a los navegantes y su implantación permite realizar una gestión más eficaz optimizando los recursos disponibles y disminuyendo los gastos de explotación. Por cada ayuda supervisada, hay una estación remota que recoge información del estado de funcionamiento de dicha ayuda y la transmite a un centro de control que centraliza los datos y controla el sistema completo.

Con un sistema de supervisión remota, podemos conocer la operatividad de una ayuda a la navegación a través de la fiabilidad o capacidad con la que un equipo puede desempeñar la función para la que ha sido diseñado. Asimismo, se analiza la disponibilidad con la que, en un instante dado, una ayuda se encuentre en funcionamiento de acuerdo con los requisitos establecidos.

El sistema de supervisión remota diseñado por Puertos del Estado contempla la existencia de un centro de control por Autoridad Portuaria dotado de telecomando y de un centro de supervisión general en Puertos del Estado que permita ver el estado de todas las señales monitorizadas de cada Autoridad Portuaria. 